\title{
La estabilidad laboral. Una garantía para las víctimas de riesgo del trabajo
} en Ecuador

\section{Job stability. A guarantee for victims of risk from work in Ecuador}

\author{
Yaneth Lucia Valverde-Torres \\ us.yanhetvalverde@uniandes.edu.ec \\ Universidad Regional Autónoma de los Andes, Santo Domingo \\ Ecuador \\ https://orcid.org/0000-0002-0891-286X \\ Jefferson Santiago Carrera-Pallares \\ ds.jeffersonscp16@uniandes.edu.ec \\ Universidad Regional Autónoma de los Andes, Santo Domingo \\ Ecuador \\ https://orcid.org/0000-0002-8641-3804
}

Recepción: 15 de septiembre 2021

Revisado: 25 octubre 2021

Aprobación: 15 de noviembre 2021

Publicación: 01 de diciembre 2021 


\section{Estimado Editor (a):}

La Constitución del Ecuador garantiza a las personas trabajadoras el derecho a desarrollar sus labores en un ambiente adecuado y propicio, que garantice su salud, integridad, seguridad, higiene y bienestar. (Constitución de la República del Ecuador, 2008). En este sentido se titifica lo siguiente:

Artículo. 325.- El Estado garantizará el derecho al trabajo. Se reconocen todas las modalidades de trabajo, en relación de dependencia o autónomas, con inclusión de labores de autosustento y cuidado humano; y como actores sociales productivos, a todas las trabajadoras y trabajadores.

Por otro lado, el riesgo laboral está presente en los diferentes espacios donde laboran los trabajadores al respecto Capa Benítez, Flores Mayorga y Sarango Ortega (2018) manifiestan:

Los trabajadores están expuestos a muchos factores de riesgos ocupacionales durante el desempeño de sus labores, es por ello que el desconocimiento de dichos riesgos o los parámetros bajo los que se desempeñe cada empleado se convierten en inseguridades laborales. (p.336)

De lo antes señalado, determina la importancia del reconocimiento constitucional e infra constitucional sobre el riesgo del trabajo, por cuanto el trabajador amerita el irrestricto respeto por sus derechos en materia del contexto donde ejerce sus labores. El Derecho laboral, se rige por principios, que en esencia son protectores de los derechos de los trabajadores, entre los que se tiene como principales: indubio prooperario, primacía de la realidad, intangibilidad, irrenunciabilidad, igualdad y no discriminación, buena fe, equidad, justicia social, continuidad, este último de interés en esta investigación. Por lo tanto, para Rosales Quichimbo, García Muñoz y Durán Ocampo (2019):

La aplicación de las normas jurídicas laborales son uno de los factores que estructuran el trabajo como relación social; el cumplimiento del contenido del Código del Trabajo es un buen indicador del estado de la relación de poder entre capital y trabajo asalariado. (p.107) 
El actio legis, desde el principio de continuidad, también conocido como principio de estabilidad, es uno de los más fundamentales para la comprensión del derecho laboral, porque garantiza efectivamente la permanencia del trabajador en su sitio de trabajo en la relación laboral. Por ello, la estabilidad laboral reforzada se inspira en el principio de estabilidad laboral como una garantía y permanecía en el trabajo de esta manera surge su evolución, por medio de la jurisprudencia más adelante citada, que deja de ser simplemente estabilidad laboral, sino que viene a ser reforzada, en donde va a garantizar la protección a los trabajadores en las situaciones de mayor vulnerabilidad, actos donde el trabajador se encuentre en debilidad.

Sin embargo, en el Ecuador actualmente no se encuentra normada como tal la estabilidad laboral reforzada, aun teniendo en cuenta que la estabilidad laboral la tienen mujeres embarazadas, mujeres en periodo de lactancia y dirigentes sindicales, es por ello que, la Corte Constitucional de Ecuador en algunos de sus pronunciamientos hace ver que también las personas que son víctimas de riesgos laborales deben de poseer esta condición especial de estabilidad, como en la Sentencia No $375-17-S E P-C C$.

En tal sentido, la estabilidad laboral reforzada se encuentra reconocida a favor de las mujeres embarazadas, mujeres en periodo de lactancia y dirigentes sindicales, pero nada dice respecto al derecho de la persona víctima de accidente de trabajo. En este sentido, la estabilidad laboral reforzada tiene como objeto proteger a los trabajadores, con la finalidad que gocen de igualdad, y la garantía de la permanecía del empleo en particular cuando suceden actos de discriminación. Es importante mencionar que, actualmente esta garantía -como se dijo-, se encuentra reconocida en la línea jurisprudencial de la Corte Constitucional del Ecuador

De esa manera se puede determinar como el derecho va evolucionando en su desarrollo jurídico, y va adquiriendo mayor relevancia, amplitud, en la rama del Derecho laboral, por medio de las diferentes doctrinas y sentencias emitidas por en otros países, como es el caso de la Corte Constitucional Colombiana, en donde sí se garantiza el principio de estabilidad laboral reforzada. 
Al respecto, la estabilidad laboral reforzada nace como fruto de la jurisprudencia constitucional, más no como ordenamiento normativo expreso. A nivel del derecho comparado, por parte de la Corte Constitucional de Colombia, se ha considerado que la garantía de la estabilidad laboral reforzada es:

La que tiene todo trabajador a permanecer en el empleo y a obtener los correspondientes beneficios salariales y prestacionales, incluso contra la voluntad del patrono, si no existe una causa relevante que justifique el despido. (Sentencia No. T-041, 2014)

Así mismo, en Chile, durante los últimos diez años, el Ministerio del Trabajo y Previsión Social, ha establecido únicamente un conjunto de políticas públicas a fin de frenar lo que se ha denominado en dicho país como los riesgos psicosociales del trabajo, frente a lo cual se ha diseñado un protocolo de vigilancia, el que busca registrar la existencia y magnitud de estos factores, elaborando recomendaciones para disminuir la incidencia y prevalencia del estrés laboral, además de otros problemas relacionados con la salud mental de los trabajadores. (Protocolo de Vigilancia de Riesgos Psicosociales en el trabajo, 2013)

En Perú al igual que en Chile, se ha establecido una política pública preventiva, creando el Plan Nacional de Seguridad y Salud en el Trabajo, cuya finalidad es "promover una cultura de prevención de riesgos laborales, a través del desarrollo de actividades que den cumplimiento a los lineamientos establecidos en la Política Nacional de Seguridad y Salud en el Trabajo" (Plan Nacional de Seguridad y Salud en el Trabajo, 2016). Con la vigencia de este plan, tanto empresas como profesionales de la salud ocupacional y trabajadores, asuman su responsabilidad en estas materias. Por consiguiente, el Derecho Laboral es producto de un proceso histórico de la sociedad ecuatoriana que forma parte del Derecho Social puesto que su orientación es la de proteger al actor económico "fuerza laboral" que no posee el capital. (Chiriboga Izquieta, Jiménez y Toscanini Sequeira,2018, p.227).

En este sentido, el trabajo debe reconocerse como un derecho, en concordancia con lo manifestado por Velaña Bayas (2019): 
Es decir, el trabajo es un derecho reconocido a nivel nacional como internacional el mismo que es fuente de realización personal y base de la economía para garantizar una vida digna en sociedad, para lograr mejorar su calidad de supervivencia. (p.20)

De acuerdo a los alegatos, se ha determinado que un riesgo de trabajo es un hecho mediante el cual se ve afectado la salud del empleado producto de su labor, mismo que se clasifica en accidentes o enfermedades profesionales. Pero estos hechos pueden provocar un despido, lamentablemente, existen normas y vacíos legales que permiten o dan facilidad a los empleadores para aplicar los despidos intempestivos en las empresas privadas, en ciertos casos aprovechando la ingenuidad del colaborador que, por lo general, desconoce de sus derechos. (Cuenca Ullaguari 2016, p.7).

Es evidente y lamentable que en el Ecuador actualmente no existe una ley que garantice la estabilidad laboral a favor de las víctimas de riesgos del trabajo, es decir en Ecuador no se encuentra garantizada la estabilidad laboral reforzada a favor de los trabajadores víctimas de riesgos de trabajo, lo cual denota que no se encuentra en la normativa este beneficio, considerando que los derechos deben ser garantizados de forma progresiva conforme el artículo 11 literal 8 de la Carta Magna, pero de lo cual, existe la jurisprudencia constitucional que constituye una fuente directa del derecho que dispone precedente en el tema de enfermedad profesional, sin embargo, no hay existe disposición normativa respecto del accidente de trabajo.

Resulta imperioso que el legislador ecuatoriano a través de sus facultades constitucionales incluya la institución jurídica de la estabilidad reforzada a favor de víctimas de riesgos de trabajo, y de esta forma se brinde dicha protección especial conforme la Constitución y los Tratados y Convenios Internacionales

\section{FINANCIAMIENTO}

No monetario.

\section{AGRADECIMIENTO}

A la Universidad Regional Autónoma de los Andes, Santo Domingo, por motivar el desarrollo de la Investigación. 


\section{REFERENCIAS CONSULTADAS}

Asamblea Nacional Constituyente de la República del Ecuador, (2008). Constitución de la República del Ecuador. [Constitution of the Republic of Ecuador]. Montecristi. Registro Oficial 449 de 20-oct-2008. Recuperado de https://n9.cl/sia

Capa Benítez, L., Flores Mayorga, C., y Sarango Ortega, Y. (2018). Evaluación de factores de riesgos que ocasionan accidentes laborales en las empresas de Machala-Ecuador. [Evaluation of risk factors that cause occupational accidents in the companies of Machala-Ecuador]. Revista Universidad y Sociedad, 10(2), 341-345. Recuperado de: https://n9.cl/va4p2

Corte Constitucional de Colombia (2013) Sentencia T-041/14. [ Judgment T-041/14]. Recuperado de: https://n9.cl/3vpo1

Corte Constitucional de Ecuador (2013) Sentencia No. 375-17-SEP-CC. [Judgment No. 375-17-SEP-CC]. Recuperado de: https://n9.cl/nsyzm

Cuenca Ullaguari, M. (2016) Análisis socio jurídico sobre la estabilidad laboral en el sector privado ecuatoriano y sus consecuencias en los despidos intempestivos. [Socio-legal analysis on job stability in the Ecuadorian private sector and its consequences on untimely dismissals]. Tesis de Pregrado. Universidad Nacional de Loja. Ecuador.

Chiriboga Izquieta, H., Jiménez, E., y Toscanini Sequeira, P. (2018). El derecho laboral como herramienta política, una mirada histórica. [Labor law as a political tool, a historical look]. Revista Universidad y Sociedad, 10(1), 226-231. Recuperado de: https://n9.cl/rij4l

Ministerio del Trabajo Colombia (2014) Plan Nacional de Seguridad y Salud en el Trabajo 2013-2021. [ National Plan for Safety and Health at Work 2013-2021]. Recuperado de: https://n9.cl/tlmh

Ministerio de Salud Chile (2013) Protocolo de Vigilancia de Riesgos Psicosociales en el Trabajo. [Protocol for the Surveillance of Psychosocial Risks at Work]. Recuperado de: https://n9.cl/hpjt

Rosales Quichimbo, C., García Muñoz, S., y Durán Ocampo, A. (2019). Algunas consideraciones sobre la aplicación del derecho laboral. Machala, Ecuador. [Some considerations on the application of labor law. Machala, Ecuador]. Revista Universidad y Sociedad, 11(4), 106-117. Recuperado de: https://n9.cl/eisbe 
Velaña Bayas, B. (2019) La afectación del derecho al trabajo de los servidores públicos ocasionado por los contratos ocasionales en el Ecuador. [The impact on the right to work of public servants caused by occasional contracts in Ecuador] Boletín de Coyuntura, 22,20-23 UTA. DOI: http://dx.doi.org/10.31164/bcoyu.22.2019.720

(C2021 por los autores. Este artículo es de acceso abierto y distribuido según los términos y condiciones de la licencia Creative Commons Atribución-NoComercial-Compartirlgual 4.0 Internacional (CC BY-NC-SA 4.0) (https://creativecommons.org/licenses/by-nc-sa/4.0/). 